\title{
The Usefulness of the Bone Marrow Examination in the Investigation of the Acquired Immune Deficiency Syndrome: The Harris County Hospital District Experience
}

M. Qasim Ansari, M.D. and Eugenio I. Banez, M.D.

Houston, Texas

DOI: http://dx.doi.org/10.5915/23-1-15222

\begin{abstract}
A retrospective examination of bone marrow biopsies of sixty one consecutive patients with acquired immune deficiency syndrome (AIDS) was performed in order to delineate the morphology of the disease and to determine the usefulness of bone marrow examination in AIDS. The morphologic features were compared with those reported in the literature. Common findings included hypercellularity (76\%), increased M:E ratio (35\%), increased megakaryocytes (50\%), plasmacytosis (36\%), fibrosis (90\%) increased iron stores $(77 \%)$, benign lymphohistiocytic proliferations (38\%) and granulomas (30\%). Acid fast bacilli were demonstrated in $11 \%$ and fungi in 10\%. The authors conclude that there are changes in the bone marrow in most cases of AIDS and the findings though nonspecific are fairly characteristic. The bone marrow biopsy was found to be a very useful tool in the diagnosis of opportunistic diseases and in the proper classification of AIDS.
\end{abstract}

Key words: Bone marrow biopsy, AIDS, retrospective review, morphology.

Morphologic findings in the bone marrow in acquired immune deficiency sydrome (AIDS) have been reported previously. ${ }^{1-19}$ The bone marrow biopsy is used primarily for diagnosing opportunistic diseases both infectious and neoplastic. It aids in the classification of the syndrome of HIV infection according to the new guidelines of the Center for Disease Control (CDC). ${ }^{20} \mathrm{~A}$ bone marrow examination also helps elucidate hematological abnormalities

From the Department of Pathology

Baylor College of Medicine, and

Ben Taub General Hospital, Houston, TX

Reprint Requests: M. Qasim Ansari, M.D.

Department of Pathology, Baylor College of Medicine

One Baylor Plaza, Houston, TX 77030

Phone (713) 798-4661 that are common in AIDS. Lately, with the availability of serological tests for the human immunodeficiency virus (HIV) antibody, the bone marrow biopsy is being performed in fewer patients. This retrospective study seeks to determine the usefulness of this procedure. We present the experience of the Harris County Hospital District (HCHD) which has the fourth largest population of AIDS patients in the United States, and compare our morphological findings with similar studies in the literature.

\section{Material and methods}

Bone marrow biopsy specimens were obtained from sixty one patients with clinically diagnosed AIDS from January 1985 to July 1987 . The disease was diagnosed according to the CDC criteria as they evolved. Biopsies were obtained with a Jamshidi needle from the posterior superior iliac crest. The specimens were fixed in Zenker's solution for 5-6 hours and processed routinely. Five step sections of 


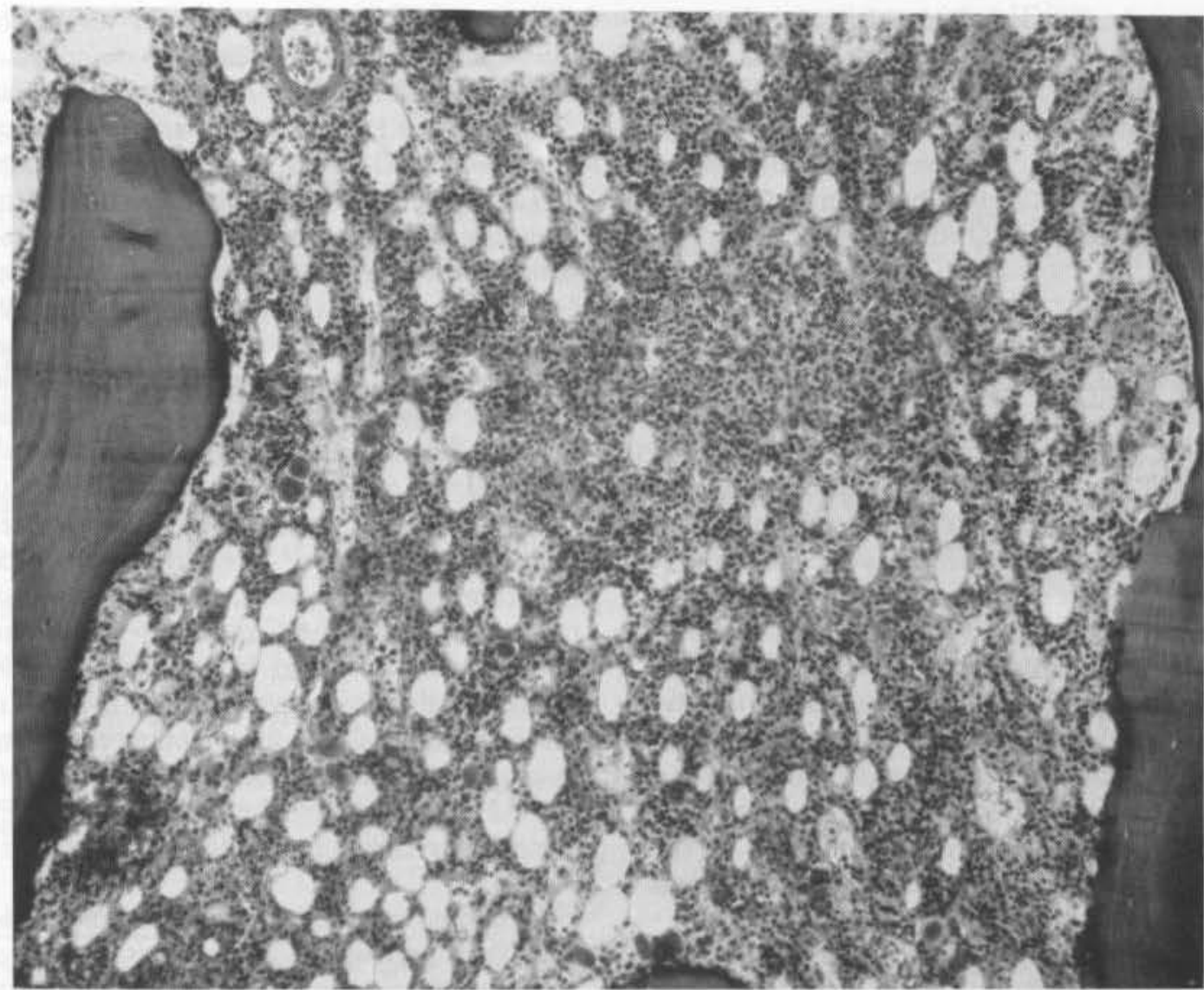

Figure 1. Low power photomicrograph of a bone marrow biopsy in an AIDS patient showing marked hypercellularity.

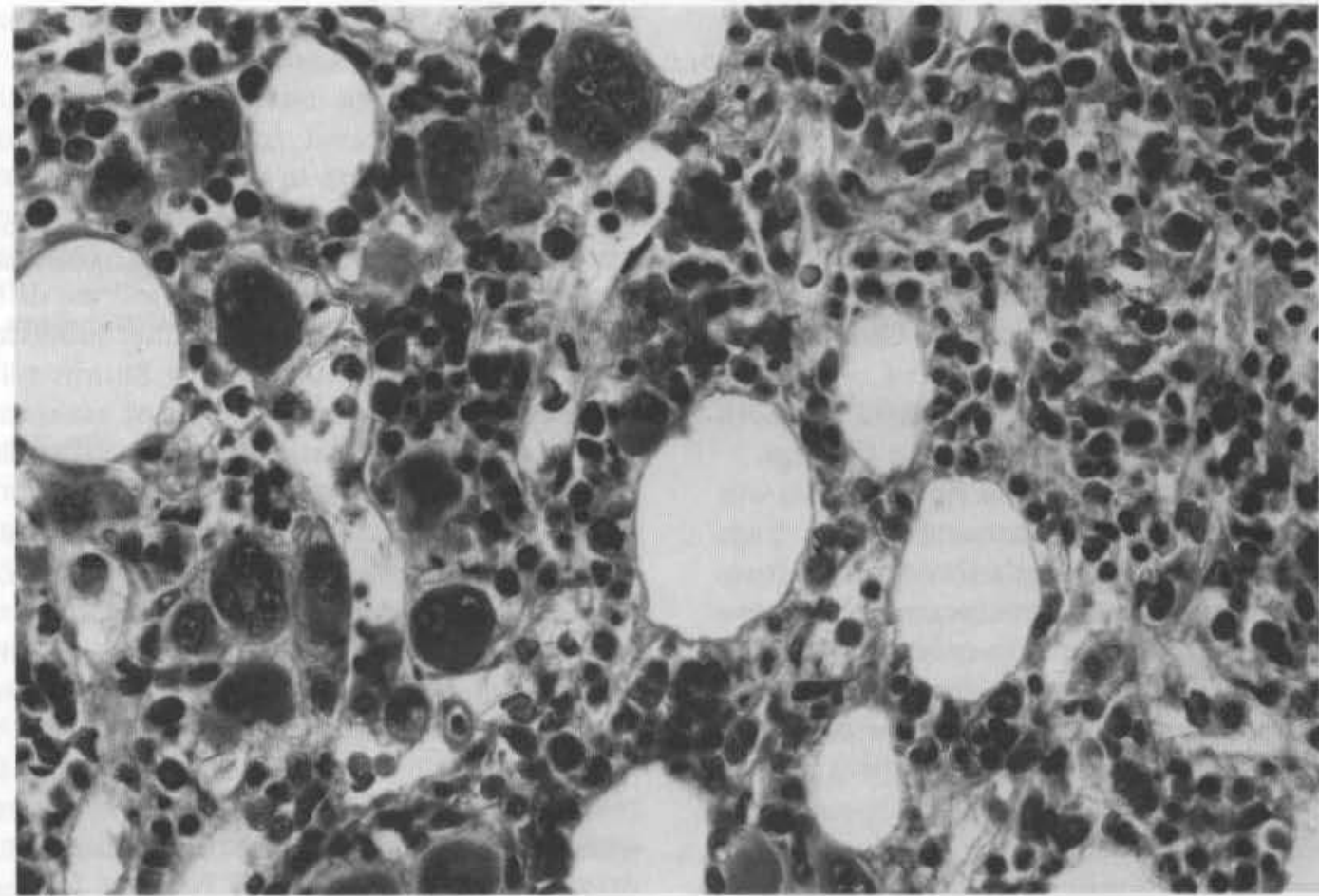

Figure 2. High power view of the bone marrow in an AIDS patient showing hypercellularity, increased M:E ratio and marked increase in the number of megakaryocytes. The distended sinuses indicate increased fibrosis which is better seen with reticulin stains. 
the appropriately dehydrated, decalcified and paraffin embedded tissues, each about 5 microns thick, were cut and stained. In addition to hematoxylineosin, the following stains were employed routinely: Gomori's iron stain, Snook's reticulin stain, Kinyoun's stain for acid fast bacilli and Grocott's silver methenamine stain (GMS).

\section{Results}

Bone marrow biopsies from AIDS patients constituted $10.2 \%(61 / 598)$ of all bone marrow biopsies received at the HCHD pathology laboratories from January 1985 through July 1987 . The age range of patients was 21-49 years. There was only one woman. Thirty six patients were white, 22 were black and 3 were hispanic. Hypercellularity was a common finding. Seventy six percent of our patients had increased cellularity. Ten percent had decreased cellularity and one patient had an aplastic picture. Megakaryocytes were increased in $50 \%$ and decreased in $5 \%$. One to four megakaryocytes per 1,000 nucleated cells was considered normal. The myeloid to erythroid (M:E) ratio was increased in $35 \%$, and was decreased in $15 \%$. Plasma cells were increased in $36 \%$ of the biopsies (up to $2 \%$ is considered normal). Typical findings are shown in figures 1 and 2 .

Thirty eight percent of cases had one or more small to medium sized lymphohistiocytic aggregates. The aggregates consisted mostly of small lymphocytes with scattered histiocytes. A few cases had a diffuse increase in histiocytes. Diffuse non-Hodgkin's lymphoma was present in 2 cases. One case had a Burkitt's lymphoma-like picture and the other was immunoblastic.

Non-caseating granulomas were present in $30 \%$ of the cases. They were small and consisted mostly of epithelioid histiocytes. Acid fast bacilli were found in seven cases $(11 \%)$ and fungi were demonstrated in 6 cases $(10 \%)$. Only 9 of 18 granulomas had organisms on special stains ( 5 on AFB and 4 on GMS). Three cases with no granulomas demonstrated organisms: one had AFB, one had fungi and the third had both AFB and fungi. Table 2 illustrates these findings.

Ninety percent of our cases had fibrosis. This was noted mainly on reticulin stains and ranged from mild to moderate degrees. Each showed a diffuse, delicate pattern. A normal bone marrow was considered to be reticulin free or with only rare scattered fine perivascular and peritrabecular reticulin fibers. Iron stores were increased in $72 \%$ of our cases and decreased in $10 \%$. Serous atrophy of fat was present in $5 \%$ of the biopsies.

\section{Discussion}

The bone marrow morphology in AIDS has been described previously (Table 1 ). ${ }^{1-19}$ Characteristic changes have been described but no pathognomonic picture has emerged. Geller and co-workers had sug- gested a diagnostic "AIDS pattern" in the bone marrow. The important features described include hematopoietic cells separating but not effacing fat cells, a diffuse increase in immature granulocytes and increased $\mathrm{M}: \mathrm{E}$ ratio, an increased number of megakaryocytes and eosinophils, scattered clusters of large sized lymphocytes and increased reticulin. The separation of fat cells by the hematopoietic cells was considered the most important morphologic feature of the marrow. Like other investigators we have been unable to see this particular fat distribution consistently. However the other findings were seen in a majority of our cases.

The bone marrow is usually hypercellular. ${ }^{1,3,11}$ Shenoy and co-workers reported increased cellularity in $86 \%$ of their cases. ${ }^{3}$ The M:E ratio was increased in a third of our patients. Other authors have also reported increased $\mathrm{M}: \mathrm{E}$ ratios. ${ }^{1,3,18}$ The association of hypercellularity and an increased M:E ratio indicates myeloid hyperplasia which is likely reactive. Marrow hypoplasia is an uncommon finding. ${ }^{2,3,8,15}$ Suggested mechanisms include altered $T$-cell function and AFB infection. ${ }^{2},{ }^{3}$ The association of AFB infection with erythroid hypoplasia has also been observed. ${ }^{2,16}$

Lymphoid aggregates have been reported in $10-86 \%$ of patients. ${ }^{1-6,8,15,16}$ These usually consist of small lymphocytes with a few epithelioid histiocytes, not unlike our findings. Osborne and co-workers reported irregular lymphocytes in these aggregates which they had difficulty distinguishing from $\mathrm{T}$ cell lymphoma.' After Kaposi's sarcoma, malignant lymphomas constitute the second most common form of malignant neoplasia seen in AIDS. Ziegler first reported an increased incidence of diffuse nonHodgkin's lymphoma in patients with AIDS. ${ }^{21}$ According to Knowles, the most common histopathological type of malignant lymphoma occuring in association with AIDS is "the diffuse undifferentiated type" which is further subdivided into two types, the Burkitt's and the Burkitt's-like lymphoma.' The other major types of malignant lymphoma seen in these patients are the diffuse large cell and diffuse large cell immunoblastic lymphomas. All of these types of lymphoma seen in AIDS have been shown to be of the B-cell type. They usually present with disseminated disease and are poorly responsive to therapy.

Increased plasma cells in the bone marrow may be due to polyclonal activation of B cells in these patients. ${ }^{22}$ Spivak and co-workers suggested that the plasmacytosis in AIDS may be due to both persistent antigenic stimulation by micro-organisms as well as defective regulation of $\mathrm{B}$ cell function. ${ }^{4}$

An increase in reticulin fibers is almost always demonstrable. Ninety percent of our cases had a diffuse increase in reticulin fibers. The cause of fibrosis is not clear. Geller and co-workers have commented 
Table 1. Comparison of morphologic findings in the bone marrow in patients with AIDS.*

\begin{tabular}{|c|c|c|c|c|c|c|c|c|}
\hline & & $\begin{array}{c}\text { Present } \\
\text { Study }\end{array}$ & $\begin{array}{l}\text { Geller } \\
\text { et al }^{1}\end{array}$ & $\begin{array}{c}\text { Shenoy } \\
\text { and } \operatorname{Lin}^{3}\end{array}$ & $\begin{array}{c}\text { Osborne } \\
{\text { et } \mathrm{al}^{5}}^{5} \\
\end{array}$ & $\begin{array}{c}\text { Castella } \\
\text { et } \mathrm{al}^{2}\end{array}$ & $\begin{array}{c}\text { Spivak } \\
\text { et al }{ }^{4}\end{array}$ & $\begin{array}{l}\text { Namiki } \\
\text { et al's }\end{array}$ \\
\hline \multicolumn{2}{|l|}{ Number of cases } & 61 & 30 & 35 & 32 & 55 & 12 & 41 \\
\hline Cellularity & $\begin{array}{l}\text { Increased } \\
\text { Decreased }\end{array}$ & $\begin{array}{l}76 \\
10\end{array}$ & $\begin{array}{c}53 \\
\mathrm{NR}\end{array}$ & $\begin{array}{r}86 \\
9\end{array}$ & $\begin{array}{l}\text { NR } \\
\text { NR }\end{array}$ & $\begin{array}{l}16 \\
17\end{array}$ & $\begin{array}{l}42 \\
25\end{array}$ & $\begin{array}{l}17 \\
27\end{array}$ \\
\hline M:E ratio** & Increased & 35 & 86 & NR & NR & 24 & NR & NR \\
\hline Megakaryocytes & $\begin{array}{l}\text { Increased } \\
\text { Decreased }\end{array}$ & $\begin{array}{r}50 \\
5\end{array}$ & $\begin{array}{c}58 \\
\text { NR }\end{array}$ & $\begin{array}{r}18 \\
\text { NR }\end{array}$ & $\begin{array}{l}\text { NR } \\
\text { NR }\end{array}$ & $\begin{array}{l}35 \\
10\end{array}$ & $\begin{array}{l}\text { NR } \\
\text { NR }\end{array}$ & $\begin{array}{l}\text { NR } \\
\text { NR }\end{array}$ \\
\hline \multicolumn{2}{|c|}{ Lymphohistiocytic Proliferation } & 38 & 86 & 37 & 38 & 10 & 58 & 22 \\
\hline \multicolumn{2}{|l|}{ Lymphoma } & 3 & NR & NR & NR & NR & NR & 22 \\
\hline \multicolumn{2}{|l|}{ Plasmacytosis } & 36 & NR & 63 & 31 & 78 & 100 & 59 \\
\hline \multicolumn{2}{|l|}{ Granulomas } & 30 & 0 & 12 & 7 & 15 & 0 & 24 \\
\hline \multirow[t]{2}{*}{ Special Stains: } & $\mathrm{AFB} \dagger$ & 11 & 0 & 3 & 3 & 11 & 0 & 10 \\
\hline & GMS $+\dagger$ for fungi & 10 & NR & NR & 3 & NR & NR & 5 \\
\hline \multicolumn{2}{|l|}{ Fibrosis } & 90 & 87 & 50 & NR & 53 & 90 & NR \\
\hline Iron Stains & $\begin{array}{l}\text { Increased } \\
\text { Absent/Decreased }\end{array}$ & $\begin{array}{l}72 \\
10\end{array}$ & $\begin{array}{l}\text { ND } \\
\text { ND }\end{array}$ & $\begin{array}{r}94 \\
6\end{array}$ & $\begin{array}{c}\text { NR } \\
50\end{array}$ & $\begin{array}{l}53 \\
24\end{array}$ & $\begin{array}{l}\text { NR } \\
\text { NR }\end{array}$ & $\begin{array}{l}39 \\
19\end{array}$ \\
\hline \multicolumn{2}{|c|}{ Serous Atrophy/Necrosis } & 5 & NR & 19 & 22 & NR & 33 & 34 \\
\hline
\end{tabular}

*All values are in percents except for the number of cases.

**Myeloid: Erythroid ratio.

$\dagger$ Acid fast bacilli

††Grocott's Silver methenamine stain.

Table 2. Breakdown of granulomatous inflammation and organisms on bone marrow biopsy in 61 cases of AIDS.

\begin{tabular}{lccccc}
\hline & $\begin{array}{c}\text { No. of } \\
\text { Cases }\end{array}$ & AFB $^{*}$ & Fungi & $\begin{array}{c}\text { AFB } \\
\text { and Fungi }\end{array}$ & $\begin{array}{c}\text { No Organisms } \\
\text { Seen }\end{array}$ \\
\hline With granulomas & 18 & 5 & 4 & 0 & 9 \\
Without granulomas & 43 & 1 & 1 & 1 & 40 \\
Total & 61 & 6 & 5 & 1 & 49 \\
\hline
\end{tabular}

*Acid fast bacilli

on the uncertainty of both the etiology and time course of the fibrosis. ${ }^{l}$ They reported increased reticulin fibers in $87 \%$ of their cases and Spivak in $90 \% .4$ Shenoy reported fibrosis in only $50 \%$ of their cases and commented that the low figure could be due to a different patient population in their study. ${ }^{3}$ Only Treacy et al failed to demonstrate fibrosis in the bone marrow in their cases. ${ }^{16}$

Granulomas were seen in a third of our patients. We were able to identify organisms, using special stains, in $50 \%$ of this subgroup of patients. (See Table 2). Namiki et al had a similar experience. ${ }^{15}$ Jagadha et al found granulomas in 6 of 8 patients with AIDS. ${ }^{17}$ They believe that granulomas in AIDS are produced independent of cell-mediated immune mechanisms, similar to granulomas produced in immunocompromised experimental animals. Castella and co-workers reported that $11 \%$ of their cases were positive for mycobacteria. ${ }^{2}$ These figures are not different from those reported for miliary tuberculosis where $15-40 \%$ of bone marrow examinations have been shown to be positive. ${ }^{24}$ Farhi and co-workers have looked at cases with disseminated mycobacterium avium intracellulare infections and found that $50 \%(6 / 12)$ of those with granulomas $(12 / 24)$ had a positive microbiological culture but only $7 \%$ (1 of 12) had a positive stain for acid fast bacilli. ${ }^{23}$ This emphasizes the importane of 
microbiological culture of the bone marrow in these cases. A fluorescent method to demonstrate the presence of mycobacteria in the marrow has been shown to be more reliable and faster than the traditional AFB stains. ${ }^{14}$

None of the described morphological changes are specific or pathognomonic of AIDS. Indeed, Namiki et al reported that bone marrow findings in patients with AIDS are similar to those in patients with AIDS related conditions. ${ }^{15}$ The causes of these morphological changes in the bone marrow are probably multiple and may include direct effect of the HIV virus, opportunistic infections, altered immune mechanisms or drug therapy. Based on this series as well as on those of others, combinations of morphologic features were found to be fairly characteristic of the syndrome and in our experience, some cases were readily recognizable as "AIDS marrow". The bone marrow biopsy was definitive of AIDS during that portion of the study period when the presence of an opportunistic disease was necessary for the diagnosis. In the latest classificaiton of HIV infection formulated by the CDC, ${ }^{20}$ bone marrow biopsy is part of the diagnostic work-up in defining group IV-C and IV-D, the former being the presence of opportunistic infection and the latter, of neoplasm. Frequently, the diagnosis of infection is made first and only in the bone marrow. It is a safe, inexpensive and easily performed procedure, with a short turn around time. In our study it yielded positive results for opportunistic infecion or neoplastic disease in $38 \%$ (23/61) of cases. Therefore it is felt that the bone marrow biopsy examination is useful at least in the investigation of patients in illdefined syndromes and where the establishment of a histologic diagnosis of granulomatous disease or a neoplasm would form the basis for initial therapy.

\section{References}

1. Geller SA, Muller R, Greenberg ML, Siegal FP, et al: Acquired immunodeficiency syndrome: Distinctive features of bone marrow biopsies. Arch Pathol Lab Med 1985; 109:138-41.

2. Castella A, Croxson TS, Mildban D, Wilt DH, et al: The bone marrow in AIDS. Am J Clin Pathol $1985 ; 84: 425-32$.

3. Shenoy $\mathrm{CM}$ and $\mathrm{Lin} \mathrm{JH}$ : Bone marrow findings in acquired immunodifficiency syndrome. Am J Med Sci 1986; 292(6):273-5.

4. Spivak ZK, Bender BS, Quinn TC: Hematologic abnormalities in the acquired immunodeficiency syndrome. Am J Med 1984; 77:226-8.

5. Osborne BM, Guerder LA, Butler JJ: Bone marrow biopsis in patients with acquired immunodeficiency syndrome. Hum Pathol 1984; 15:1048-53.

6. Lake JP, Lee S, Spire S: Bone marrow findings in AIDS patients (abstract). Am J Clin Pathol 1984; 81:799-800.

7. Fauci AS, Plesur H, Crelmann EP, Markham PD, et al: The acquired immunodeficiency syndrome: An update. Ann Intern Med 1985; 102:800-13.

8. Spivak JL, Selanick SE, Quin TC: Acquired immunodeficiency syndrome and panacytopenia. JAMA 1983; 250:3084-87.

9. Knowles DM: Malignant lymphomas occurring in association with acquired immunodeficiency syndrome. Lab Med 1986; 17(11):674-8.

10. Little BJ: Case report - Kaposi's sarcoma with bone marrow involvement. Am J Med Sci 1986, 292(1):44-6.

11. Witt D, Mackey D, Schwan L, Goldstein D, et al: Acquired immune deficiency syndrome presenting as a bone marrow and mediastinal cryptococcosis. Am J Med 1987; 149(82):149-50.

12. Fahri DC, Mason UG, Horsburg CR, et al: The bone marrow in disseminated mycobacterium avium-intracellular infection. Am J Clin Pathol 1985; 83:463-68.

13. Schneider DR and Picker LJ: Myelodysplasia in the acquired immune deficiency syndrome. Am J Clin Pathol 1985; 84:144-52.

14. Uribe-Botero G, Prickard JG, Kaplowitz HJ: Bone marrow in HIV infection. A comparison of fluorescence staining and cultures in the detection of Mycobacteria. Am J Clin Pathol 1989; 91:313-15.

15. Namiki TS, Boone DC, Meyer PR: A comparison of bone marrow findings in patients with acquired immunodeficiency syndrome (AIDS) and AIDS related conditions. Hematol Onco 1987; 5:99-106.

16. Treacy M, Lai L, Costello C, Clark A: Peripheral blood and bone marrow abnormalities in patients with HIV related disease. $\mathrm{Br} \mathrm{J}$ Hematol 1987; 65:289-94.

17. Jagadha V, Andavolu RH, Huang CT: Granulomatous inflammation in the acquired immune deficiency syndrome. Am J Clin Pathol $1985 ; 85: 598-602$.

18. Amberson JB, DiCarlo EF, Metroka CE, Koizcemi JH, et al: Diagnostic pathology in the acquired immune deficiency syndrome. Arch Pathol Lab Med 1985; 109;345-51.

19. Reichert CM, Oleary TJ, Levens DL, Simrell $\mathrm{CR}$, et al: Autopsy pathology in the acquired immune deficiency syndrome. Am J Pathol 1983; 112:357.

20. Ostrow DG, Solomon SL, Mayer KH, Haverkos $\mathrm{H}$ : Classification of the clinical spectrum of HIV infection in adults. (AIDS) JAMA 1987; 1:7-16.

21. Ziegler JL, Drew WL, Miner RC, Mintz L, et al: Rosenbaum E, et al: Outbreak of Burkitt's-like lymphoma in homosexual men. Lancet 1982; 


\section{2:631-3.}

22. Lane HC, Mesur H, Edger LC, Shelen C, et al: Abnormalities of B cell activation and immunoregulation in patients with AIDS. N Engl J Med 1983; 309:453-8.

23. Fahri DC, Harsburg CR: Bone marrow in dessiminated Mycobacterium avium-intracellular infection. Lab Invest 1984; 50:19A.

24. Ellman L: Bone marrow biopsy in the evaluation of lymphoma, carcinoma and granulomatous disorders. Am J Med 1976; 60:1-7. 